\title{
Studi Kepecahan Moda Kegagalan Material A36 dengan Variasi Panjang Retak Terpusat
}

\author{
Muhammad Alif Budiman, Mohammad Nurul Misbah dan Totok Yulianto \\ Departemen Teknik Perkapalan, Fakultas Teknologi Kelautan \\ Institut Teknologi Sepuluh Nopember (ITS) 60111 Indonesia \\ e-mail: tita@na.its.ac.id
}

\begin{abstract}
Abstrak-Kecelakaan kapal sering terjadi diakibatkan kerusakan pada lambung. Lambung kapal merupakan susunan dari beberapa material baja yang dibentuk sedemikian rupa hingga menjadi suatu kesatuan utuh. Salah satu penyebab kerusakan lambung adalah timbulnya initial crack pada material penyusun lambung. Pada penelitian ini, pelat baja A36 yang sering digunakan pada lambung kapal dijadikan dalam skala ukuran spesimen pengujian. Tujuan penelitian ini yaitu menentukan fracture toughness dan tegangan kritis baja $\mathrm{A} 36$. Spesimen diberikan beban statis yang diperoleh dari hasil pengujian tarik. Beban tarik pada specimen uji tarik menghasilkan faktor intensitas tegangan digunakan untuk mengevaluasi fracture toughness dan tegangan kritis yang dapat diterima akibat initial crack. Pemodelan dilakukan sesuai dengan specimen dengan 9 variasi initial crack menggunakan software Finite Element Analysis. Berdasarkan variasi tersebut didapatkan beberapa hasil yang dibandingkan untuk mengevaluasi faktor intensitas tegangan, fracture toughness dan tegangan kritis akbiat intial crack. Untuk mengevaluasi dilakukan pengujian tarik (eksperimen) serta dua pendekatan yaitu XFEM setiap K mode I dan J-Integral. Didapatkan hasil fracture toughness material A36 dari eksperimen sebesar 1413.7154 MPa $\sqrt{\mathbf{m m}}$; metode XFEM setiap $\mathrm{K}$ mode I mengahasilkan fracture toughness A36 sebesar 1412.6214 $\mathrm{MPa} \sqrt{\mathbf{m m}}$ dan J-Integral menghasilkan fracture toughness A36 sebesar 1414.7809 $\mathrm{MPa} \sqrt{\mathrm{mm}}$. Perbedaan nilai fracture toughness terhadap eksperimen diperoleh eror sebesar $0.077 \%$ (XFEM setiap K mode I) dan $\mathbf{0 . 0 7 5 \%}$ (J-Integral).
\end{abstract}

Kata Kunci-Baja A36, Initial Crack, Faktor Intensitas Tegangan, J-Integral, Fracture Toughness.

\section{PENDAHULUAN}

$\mathrm{K}^{\mathrm{A}}$ APAL adalah salah satu alat transportasi yang banyak digunakan untuk mengangkut penumpang dan barang. Beberapa sektor galangan kapal menggunakan material baja A36 sebagai pondasi pembuatan struktur kapal. Pada dasarnya setiap unsur logam mempunyai keterbatasan kemampuan yang berbeda salah satunya dalam hal kekuatan. Batas kemampuan tersebut diakibatkan oleh sifar mekanik, komposisi kimia dan lain-lain. Apabila suatu logam diberikan beban diluar kemampuannya maka struktur tersebut berpotensi mengalami kegagalan. Salah satu kegagalan yang terjadi pada kapal adalah kepecahan. Kepecahan terjadi diawali dengan timbulnya suatu pengintian retak (crack initiation) jika dibiarkan akan terjadi perambatan retak (crack propagation) dan akhirnya patah/pecah (fracture).

Kegagalan struktur pada kapal terjadi karena semua tegangan-tegangan yang terjadi pada penampang strukturnya melebihi dari yang sudah ditentukan. Struktur mengalami kegagalan dapat disebabkan karena penggunaan yang tidak sesuai dengan prosedur, perawatan jarang dilakukan serta terdapat struktur yang sengaja dibangun tidak sesuai pada desain untuk memenuhi kondisi tersebut. Hal ini akan memberikan dampak negatif pada keselamatan.

Oleh karena itu, diperlukan adanya suatu penelitian untuk menganalisa kekuatan suatu material A36 ditinjau dari sifat kepecahannya. Cara yang digunakan yaitu menggunakan analisis elemen hingga. Analisis tersebut dapat mendeteksi besarnya suatu kerusakan pada struktur dengan pemodelan tertentu.

\section{STUDI LITERATUR}

\section{A. Baja Karbon}

Baja karbon terdiri atas unsur besi (Fe) dan karbon (C) dimana besi merupakan unsur utama dan karbon sebagai unsur paduan utama. Baja karbon juga mengandung penambahan unsur-unsur lain seperti sulfur (S), fosfor (P), silikon (Si), Mangan (Mn), dan sebagainya sesuai dengan sifat baja yang diinginkan. Perbedaan persentase karbon dalam campuran logam baja menjadi salah satu cara mengklasifikasikan baja [1]. Berdasarkan kandungan karbon, baja dibagi menjadi tiga macam, yaitu:

1) Baja karbon rendah

Baja karbon rendah mengandung persentase karbon $0.3 \%$ C. Baja ini memiliki sifat ketangguhan dan keuletan tinggi.

2) Baja karbon menengah

Baja karbon sedang mengandung persentase karbon $0.3 \%$ C $-0.6 \%$ C. Baja ini memiliki sifat mekanis yang lebih kuat dengan tingkat kekerasan lebih tinggi dari pada baja karbon rendah.

\section{3) Baja karbon tinggi}

Baja karbon tinggi mengandung persentase karbon $0.6 \% \mathrm{C}$ $-1.5 \%$ C. Baja ini memiliki sifat tahan panas, kekerasan serta kekuatan tarik yang tinggi namun keuletannya lebih rendah.

\section{B. Pengujian Tarik}

Uji tarik adalah suatu metode yang digunakan untuk menguji kekuatan suatu material dengan cara memberikan beban gaya yang sesumbu [2]. Pengujian tarik digunakan untuk mengukur ketahanan suatu material terhadap gaya statis yang diberikan secara terus-menerus. Hasil yang didapatkan dari pengujian tarik yaitu kurva teganganregangan material seperi pada Gambar 1.

Standar pengujian tarik untuk material ASTM A36 diatur dalam ASTM STANDARD A370. Peneliti tidak mengacu pada standar pengujian dikarenakan terdapat penambahan retak pada tengah-tengah spesimen uji. Pengujian tarik dilakukan untuk memperoleh besar tegangan yang diperlukan hingga spesimen pecah. Tegangan didapatkan dari persamaan berikut:

$$
\sigma_{\text {maks }}=\frac{F_{\text {maks }}}{A_{0}}
$$


dimana:

$\sigma_{\text {maks }}=$ Tegangan Maksimum (MPa)

$\mathrm{F}_{\text {maks }}=$ Gaya maksimum $(\mathrm{N})$

$\mathrm{A}_{0} \quad=$ Luas penampang awal $\left(\mathrm{mm}^{2}\right)$

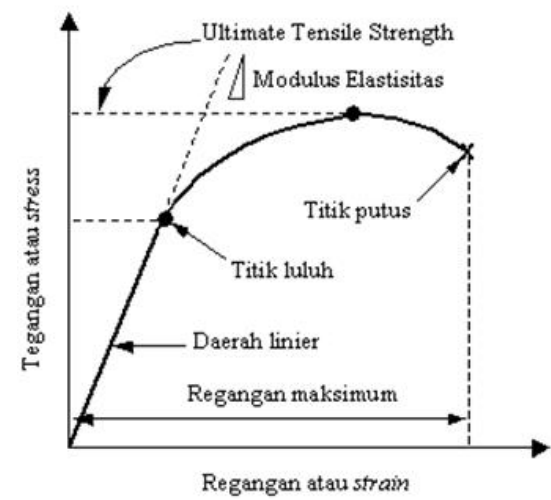

Gambar 1. Kurva Tegangan - Regangan

\section{Konsep Metode Elemen Hingga}

Penggunaan metode elemen hingga memungkinkan untuk mendapatkan nilai dari respon tegangan pada suatu struktur. Prinsip dasar metode elemen hingga adalah memperlakukan suatu sistem sebagai satu kesatuan dari beberapa elemen elemen kecil yang disebut finite element. Suatu analisis menggunakan metode elemen hingga merupakan analisis pendekatan [3]. Sehingga hasil yang diperoleh bukan hasil analisis yang eksak. Hasil dari metode elemen hingga memiliki error. Salah satu penyebab terjadinya error yaitu kesalahan pemberian batasan. Suatu batasan dapat ditoleransi sehingga hasil analisis metode elemen hingga dapat dikatakan valid. Validasi dilakukan dengan tujuan agar hasil yang diperoleh memiliki error yang kecil.

\section{Mekanika Kepecahan}

Mekanika kepecahan merupakan salah satu metode matematis untuk mempelajari semua perilaku material dengan menggunakan analisis struktur. Dalam konsep mekanika kepecahan, mode deformasi retak digolongkan dalam 3 mode deformasi [4], yaitu:

1) Mode I (opening mode)

Retak diakibatkan oleh tegangan tarik tegak lurus terhadap arah bidang penjalaran retak.

2) Mode II (slidding mode)

Retak diakibatkan oleh tegangan geser searah dengan penjalaran retak.

\section{3) Mode III (tearing mode)}

Retak diakibatkan oleh tegangan geser pada arah melintang dan membentuk sudut dengan arah penjalaran retak.

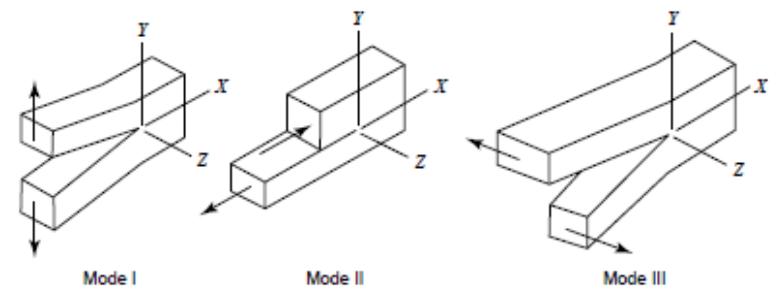

Gambar 2. Mode Deformasi Retak

\section{E. Stress Intensity Factor (SIF)}

Stress intensity factor (SIF) atau faktor intensitas tegangan merupakan fungsi dari panjang dan arah retak, geometri dan distribusi beban yang diberikan. Menurut Hertzberg [5] faktor intensitas tegangan untuk kasus retak terpusat (through thickness crack) dapat dituliskan dengan persamaan:

$$
K_{I}=\left(\frac{w}{\pi a} \tan \frac{\pi a}{w}\right) \sigma \sqrt{\pi a}
$$

dimana:

$$
\begin{aligned}
K_{I} & =\text { Stress Intensity Factor }(\mathrm{MPa} \sqrt{\mathrm{mm}}) \\
\sigma & =\text { Nominal Stress }(\mathrm{MPa}) \\
a & =\text { Panjang retak }(\mathrm{mm}) \\
\mathrm{w} & =\text { Lebar pelat }(\mathrm{mm})
\end{aligned}
$$

\section{F. J-Integral}

J-Integral merupakan suatu cara untuk menghitung faktor intensitas tegangan (SIF) pada luas permukaan retak suatu material. Menurut Rice [6] hubungan antara faktor intensitas tegangan dengan J-Integral dapat ditampilkan pada persamaan berikut:

$$
K_{I}=\sqrt{J\left(\frac{E}{1-v^{2}}\right)}
$$

dimana:

$$
\begin{array}{ll}
\mathrm{K}_{\mathrm{I}} & =\text { Faktor intensitas tegangan } \\
\mathrm{J} & =\mathrm{J} \text {-Integral } \\
\mathrm{E} & =\text { Modulus Young } \\
\mathrm{v} & =\text { Poisson ratio }
\end{array}
$$

Material baja A36 memiliki nilai modulus Young sebesar $200 \mathrm{GPa}$ dan poisson ratio sebesar $0.3 \mathrm{~mm}$.

\section{METODE PENELITIAN}

\section{A. Specimen Uji Tarik}

Spesimen uji tarik memiliki dimensi ukuran 200x30x9.6 mm dengan 9 variasi retak terpusat (through thickness crack). Variasi retak dimulai dari $4 \mathrm{~mm}-20 \mathrm{~mm}$ dengan interval 2 $\mathrm{mm}$ tiap spesimen. Spesimen uji tarik dapat dilihat pada Gambar 3.

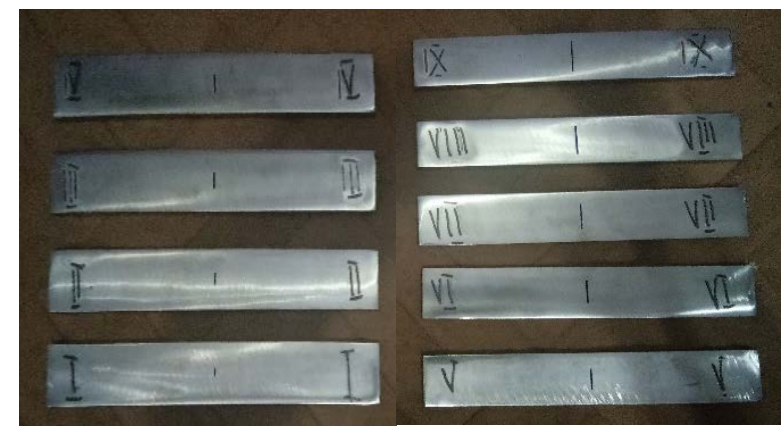

Gambar 3. Spesimen Uji Tarik

Spesimen 1 sampai 9 pada Gambar 3. Dilakukan uji tarik untuk mengetahui besar tegangan yang dibutuhkan agar spesimen pecah. Setelah dilakukan uji tarik, hasil ditampilkan pada Gambar 4.

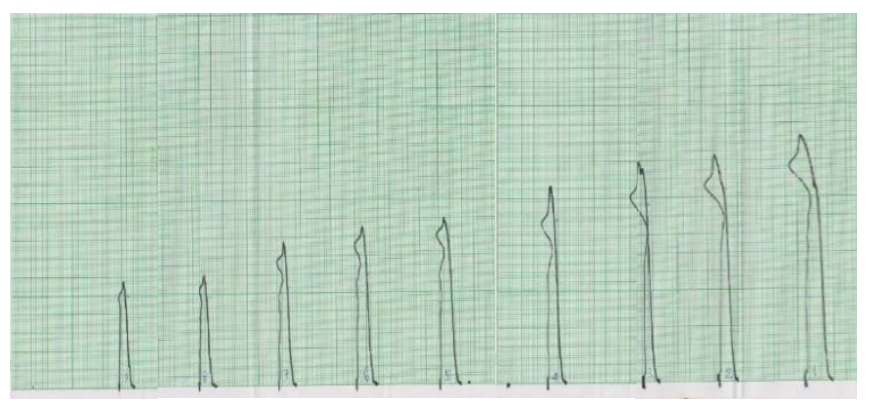

Gambar 4. Kurva Tegangan - Regangan Hasil Uji Tarik 
Pada Gambar 4. Kurva Tegangan - Regangan Hasil Uji Tarik dapat dirangkum dalam bentuk Tabel 1 .

Tabel 1

Hasil Uji Tarik masing-masing Spesimen

\begin{tabular}{ccc}
\hline \hline Material & Gaya Maksimum [kN] & Tegangan Nominal [MPa] \\
\hline I & 132 & 458.33 \\
II & 122 & 423.61 \\
III & 118 & 409.72 \\
IV & 105 & 364.58 \\
V & 88 & 305.56 \\
VI & 84 & 291.67 \\
VII & 77 & 267.36 \\
VIII & 59 & 204.86 \\
IX & 57 & 197.92 \\
\hline \hline
\end{tabular}

\section{B. Pemodelan}

Pemodelan dilakukan sesuai dengan ukuran dan jumlah variasi spesimen uji tarik dengan menggunakan finite element software. Setelah dibuat 9 variasi model, pendefinisian material properties dimasukkan pada model (ukuran spesimen uji, jenis baja, modulus young, poisson ratio). Contoh model spesimen dapat dilihat pada Gambar 5.

\section{\begin{tabular}{l|l} 
IX & IX
\end{tabular}}

Gambar 5. Model 9 dengan panjang retak $20 \mathrm{~mm}$

Pada Gambar 5 merupakan salah satu contoh model variasi spesimen. Setiap model memiliki 9 crackfront dengan 8 contour pada setiap crackfront. Namun, hasil software FEA yang diambil 6 contour dimana 2 contour dihilangkan berdasarkan nilai yang menyimpang daripada contour lainnya.

\section{Perhitungan Fracture Toughness Baja A36}

Pada penelitian ini dilakukan perhitungan fracture toughness baja A36 dengan pendekatan nilai faktor intensitas tengangan (SIF) dengan metode eksperimen dan numerik. Metode eksperimen dilakukan uji tarik untuk menemukan tegangan nominal sebagai input pada persamaan (2). Metode numerik dilakukan dua pendekatan yaitu pendekatan XFEM setiap K mode I dan J-Integral dengan bantuan software Finite Element Analysis. Setiap model akan menghasilkan satu nilai faktor intensitas tengangan (SIF) dengan mengakumulasikan nilai yang muncul pada hasil running. Nilai fracture toughness baja A36 didapatkan dengan akumulasi dari 9 model spesimen faktor intensitas tegangan (SIF) yang sudah diperoleh.

\section{Perhitungan Tegangan Kritis Baja A36}

Pada penelitian ini tegangan kritis baja A36 dihitung berdasarkan nilai fracture toughness pada setiap variasi retak yang terjadi. Tegangan kritis dapat dihitung dengan menggunakan persamaan:

$$
\sigma_{c}=\frac{K_{I C}}{\sqrt{\pi a\left(\frac{w}{\pi a} \tan \frac{\pi a}{w}\right)}}
$$

dimana:

$$
\begin{array}{ll}
\sigma_{c} & =\text { Critical Stress }(\mathrm{MPa}) \\
K_{I C} & =\text { Fracture Toughness }(\mathrm{MPa} \sqrt{\mathrm{mm}}) \\
a & =\text { Panjang retak }(\mathrm{mm}) \\
w & =\text { Lebar pelat }(\mathrm{mm})
\end{array}
$$

\section{E. Langkah Pengerjaan}

Langkah kerja penelitian ini adalah sebagai berikut:

\section{1) Pengumpulan Data}

Pengumpulan data dilakukan studi literatur yang bertujuan untuk merumuskan masalah yang berkaitan dengan penelitian yang akan dianalisis.

\section{2) Penentuan Spesimen Uji Tarik}

Penentuan ukuran spesimen dilakukan berdasarkan 9 variasi panjang retak terpusat dengan skala spesimen uji tarik. 3) Pemodelan

Pemodelan geometri dilakukan sesuai dengan ukuran spesimen uji tarik. Pemodelan ini dilakukan untuk mendapatkan tegangan yang terjadi pada spesimen untuk dianalisis.

\section{4) Konvergensi}

Konvergensi dilakukan dengan melakukan optimasi meshing pada software FEA untuk mendapatkan nilai tegangan yang konstan pada ukuran meshing optimal untuk analisis selanjutnya.

5) Analisis Stress Intensity Factor (SIF)

Analisis SIF dilakukan dengan metode eksperimen dan dua pendekatan numerik yaitu pendekatan XFEM setiap K mode I dan J-Integral.

6) Analisis Fracture Toughness (KIC)

Stress intensity factor (SIF) yang dihasilkan akan diakumulasi sehingga diperoleh fracture toughness pada masing-masing metode.

7) Analisis Tegangan Kritis

Analisis tegangan kritis dilakukan berdasarkan nilai fracture toughness baja A36.

\section{HASIL DAN PEMBAHASAN}

\section{A. Analisis Stress Intensity Factor (SIF)}

Setelah melakukan melakukan eksperimen dan pemodelan menggunakan software FEA maka tahap selanjutnya melakukan analisis faktor intensitas tegangan (SIF). Berdasarkan eksperimen dan simulasi yang dilakukan maka hasil analisis dapat ditampilkan sebagai berikut:

1) Hasil Eksperimen

Pada penelitian ini eksperimen yang digunakan adalah pengujian tarik untuk menentukan besar tegangan yang ditampilkan pada Tabel 1 Hasil Uji Tarik masing-masing Spesimen. Berdasarkan persamaan (2) perhitungan faktor intensitas tengangan (SIF) hasil eksperimen ditampilkan pada Tabel 2.

Tabel 2.

Faktor Intensitas Tengangan (SIF) Hasil Eksperimen

\begin{tabular}{ccc}
\hline \hline Material & Panjang Retak (2a) & $\mathbf{K}_{\mathbf{I}}[\mathbf{M P a} \sqrt{\mathbf{m m}}]$ \\
\hline I & $4 \mathrm{~mm}$ & 1157.3889 \\
II & $6 \mathrm{~mm}$ & 1322.5618 \\
III & $8 \mathrm{~mm}$ & 1497.4134 \\
IV & $10 \mathrm{~mm}$ & 1517.3198 \\
V & $12 \mathrm{~mm}$ & 1426.5314 \\
VI & $14 \mathrm{~mm}$ & 1515.8846 \\
VII & $16 \mathrm{~mm}$ & 1543.2637 \\
VIII & $18 \mathrm{~mm}$ & 1316.4053 \\
IX & $20 \mathrm{~mm}$ & 1426.6693 \\
\hline \hline
\end{tabular}

2) Pendekatan XFEM Setiap K Mode I

Hasil pemodelan spesimen dengan metode pendekatan XFEM dilakukan dengan menggunakan bantuan software FEA. Pada setiap model spesimen terdapat 9 crackfront dan masing-masing crackfront memiliki 8 contour. Pada penelitian ini diambil 6 dari 8 contour yang memiliki harga faktor intensitas tegangan (SIF) tidak jauh berbeda dengan 
contour lainnya. Harga SIF dengan pendekatan XFEM ditampilkan pada Tabel 3.

Tabel 3.

SIF Pendekatan XFEM

\begin{tabular}{cccc}
\hline \hline Model & K $_{\mathbf{I}}$ EKSPERIMEN & K $_{\mathbf{I}}$ XFEM & ERROR \\
\hline 1 & 1157.3889 & 1157.4259 & $0.00 \%$ \\
2 & 1322.5618 & 1332.2778 & $0.73 \%$ \\
3 & 1497.4134 & 1461.8148 & $2.38 \%$ \\
4 & 1517.3198 & 1501.5556 & $1.04 \%$ \\
5 & 1426.5314 & 1414.6481 & $0.83 \%$ \\
6 & 1515.8846 & 1519.8333 & $0.26 \%$ \\
7 & 1543.2637 & 1546.9815 & $0.24 \%$ \\
8 & 1316.4053 & 1331.0185 & $1.11 \%$ \\
9 & 1426.6693 & 1448.0370 & $1.50 \%$ \\
\hline \hline
\end{tabular}

Pada Tabel 3 merupakan hasil perbandingan harga faktor intensitas tegangan (SIF) pada metode pendekatan XFEM terhadap eksperimen. Perbedaan error terkecil pada model spesimen 1 sebesar $0.00 \%$ dan error terbesar $2.38 \%$ pada model spesimen 3. Perbedaan harga tersebut menunjukkan bahwa pada hasil running software FEA memberikan bentuk curvature (nilai acak) pada setiap crackfront sehingga harga $\mathrm{K}_{\mathrm{I}}$ tidak konstan disepanjang crackfront.

3) Pendekatan J-Integral

Berdasarkan hasil simulasi yang dilakukan maka didapatkan faktor intensitas tegangan (SIF) dengan pendekatan J-Integral. Seperti pada metode pendekatan XFEM, jumlah dan posisi contour yang ditampilkan pada pendekatan J-Integral sesuai dengan contour yang ditampilkan pada pendekatan XFEM. Perhitungan faktor intensitas tegangan (SIF) pendekatan J-Integral dihitung dengan persamaan (3) pada masing-masing model spesimen. Harga SIF pendekatan J-Integral ditampilkan pada Tabel 4.

Tabel 4.

SIF Pendekatan J-Integral

\begin{tabular}{cccc}
\hline \hline Model & K $_{\mathbf{I}}$ EKSPERIMEN & K $_{\mathbf{I}}$ J-INTEGRAL & ERROR \\
\hline 1 & 1157.3889 & 1140.5627 & $1.45 \%$ \\
2 & 1322.5618 & 1340.5513 & $1.36 \%$ \\
3 & 1497.4134 & 1463.1048 & $2.29 \%$ \\
4 & 1517.3198 & 1506.3831 & $0.72 \%$ \\
5 & 1426.5314 & 1419.5177 & $0.49 \%$ \\
6 & 1515.8846 & 1522.7885 & $0.46 \%$ \\
7 & 1543.2637 & 1554.1220 & $0.70 \%$ \\
8 & 1316.4053 & 1335.4120 & $1.44 \%$ \\
9 & 1426.6693 & 1450.5862 & $1.68 \%$ \\
\hline \hline
\end{tabular}

Pada Tabel 4. Merupakan hasil perbandingan harga faktor intensitas tengangan (SIF) pada metode pendekatan J-Integral terhadap eksperimen. Perbedaan error terkecil sebesar $0.46 \%$ pada model spesimen 6 dan erro tebesar pada model spesimen 3 sebesar 2.29\%. Perbedaan harga terjadi dikarenakan adanya perbedaan formulasi antara SIF through thickness crack dengan J-Integral. Error tidak lepas dari perbedaan harga JIntegral disepanang crackfront pada hasil running software FEA yang bersifat curvature (acak).

\section{B. Analisis Fracture Toughness $\left(K_{I C}\right)$}

Fracture toughness baja A36 diperoleh dari hasil akumulasi faktor intensitas tegangan (SIF) pada hasil eksperimen, pendekatan XFEM dan J-Integral. Harga fracture toughness ditampilkan pada Tabel 5.

Berdasarkan Tabel 5 dapat diketahui bahwa harga fracture toughness unutk material baja A36 berdasarkan hasil eksperimen, pendekatan XFEM dan J-Integral berturut-turut sebesar 1413.7154, 1412.6214 dan $1414.7809 \mathrm{MPa} \sqrt{\mathrm{mm}}$.

Tabel 5.

\begin{tabular}{cccc}
\multicolumn{4}{c}{ Akumulasi Fracture Toughness Baja A36 } \\
\hline \hline Model & $\begin{array}{c}\text { K }_{\mathbf{I}} \\
\text { EKSPERIMEN }\end{array}$ & $\mathbf{K}_{\mathbf{I}}$ XFEM & $\begin{array}{c}\mathbf{K}_{\mathbf{I}} \mathbf{J}- \\
\text { INTEGRAL }\end{array}$ \\
\hline 1 & 1157.3889 & 1157.4259 & 1140.5627 \\
2 & 1322.5618 & 1332.2778 & 1340.5513 \\
3 & 1497.4134 & 1461.8148 & 1463.1048 \\
4 & 1517.3198 & 1501.5556 & 1506.3831 \\
5 & 1426.5314 & 1414.6481 & 1419.5177 \\
6 & 1515.8846 & 1519.8333 & 1522.7885 \\
7 & 1543.2637 & 1546.9815 & 1554.1220 \\
8 & 1316.4053 & 1331.0185 & 1335.4120 \\
9 & 1426.6693 & 1448.0370 & 1450.5862 \\
$\mathbf{K}_{\mathbf{I C}}[\mathbf{M P a} \sqrt{\mathbf{m m}}]$ & $\mathbf{1 4 1 3 . 7 1 5 4}$ & $\mathbf{1 4 1 2 . 6 2 1 4}$ & $\mathbf{1 4 1 4 . 7 8 0 9}$ \\
\hline \hline
\end{tabular}

Masing-masing harga pada metode numerik memiliki nilai error terhadap hasil eksperimen sebesar $0.077 \%$ untuk pendekatan XFEM dan 0.075\% untuk pendekatan J-Integral. Error yang kecil menunjukkan bahwa perhitungan fracture toughness dengan metode pendekatan XFEM dan J-Integral cukup akurat untuk menentukan fracture toughness suatu struktur dengan kasus retak terpusat (through thickness crack).

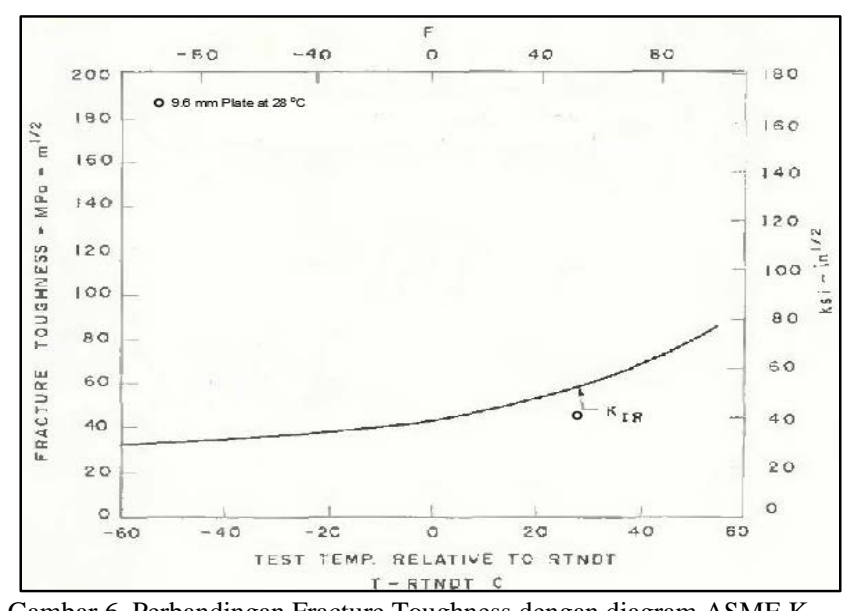

Gambar 6. Perbandingan Fracture Toughness dengan diagram ASME K

Pada Gambar 6 diagram ASME $\mathrm{K}_{\mathrm{IR}}$ fracture toughenss baja A36 pada temperatur ruangan $28{ }^{\circ} \mathrm{C}$ memiliki nilai sebesar $52 \mathrm{ksi} \sqrt{\mathrm{in}}$ setara dengan 1806.9211 MPa $\sqrt{\mathrm{mm}}$ [7]. Hasil validasi pada metode eksperimen, pendekatan XFEM dan J-Integral pada kasus retak terpusat (through thickness crack) masing-masing nilai fracture toughness memiliki error sebesar $21.76 \%$ untuk eksperimen, $21.82 \%$ untuk pendekatan XFEM dan $21.70 \%$ untuk pendekatan J-Integral tehadap fracture toughness $\left(\mathrm{K}_{\mathrm{IC}}\right)$ diagram ASME $\mathrm{K}_{\mathrm{IR}}$. Error tersebut dikarenakan geometri retak spesimen uji pada penelitian ini memiliki lebar sebesar $1 \mathrm{~mm}$ sehingga menyebabkan nilai fracture toughness menjadi lebih kecil.

\section{Perhitungan Tegangan Kritis Baja A36}

Pada penelitian ini tegangan kritis baja A36 ditinjau dari sifat kepecahannya. Sifat kepecahan yang dimaksud adalah kekuatan suatu material apabila terdapat suatu cacat berupa retak khususnya through thickness crack (retak terpusat). Berdasarkan harga fracture toughness baja A36 pada Tabel 5 dan persamaan (4) didapatkan tegangan kritis baja A36 ditampilkan pada Tabel 6 . 
Tabel 6.

Tegangan Kritis Baja A36 dengan Variasi Retak Terpusat

\begin{tabular}{|c|c|c|c|c|}
\hline \multirow{3}{*}{$\begin{array}{l}\text { Crack } \\
{[\mathrm{mm}]}\end{array}$} & \multicolumn{4}{|c|}{$\sigma_{\text {critical }}[\mathrm{Mpa}]$} \\
\hline & \multirow{2}{*}{ EKSPERIMEN } & \multicolumn{2}{|c|}{ Numeric } & \multirow{2}{*}{ ASME $K_{I R}$} \\
\hline & & XFEM & J-INTEGRAL & \\
\hline 4 & 559.8402 & 559.4070 & 560.2622 & 715.5522 \\
\hline 6 & 452.8072 & 452.4568 & 453.1485 & 578.7494 \\
\hline 8 & 386.8208 & 386.5214 & 387.1123 & 494.4097 \\
\hline 10 & 339.6891 & 339.4263 & 339.9452 & 434.1691 \\
\hline 12 & 302.8104 & 302.5761 & 303.0387 & 387.0330 \\
\hline 14 & 272.0086 & 271.7981 & 272.2136 & 347.6641 \\
\hline 16 & 244.9176 & 244.7281 & 245.1022 & 313.0382 \\
\hline 18 & 220.0047 & 219.8344 & 220.1705 & 281.1960 \\
\hline 20 & 196.1196 & 195.9679 & 196.2674 & 250.6676 \\
\hline
\end{tabular}

Berdasarkan Tabel 6 dapat diinterpretasikan dalam bentuk kurva seperti pada Gambar 6. Kurva Tegangan Kritis Baja A36.

\section{Critical Strees vs Crack $(2 a)$}

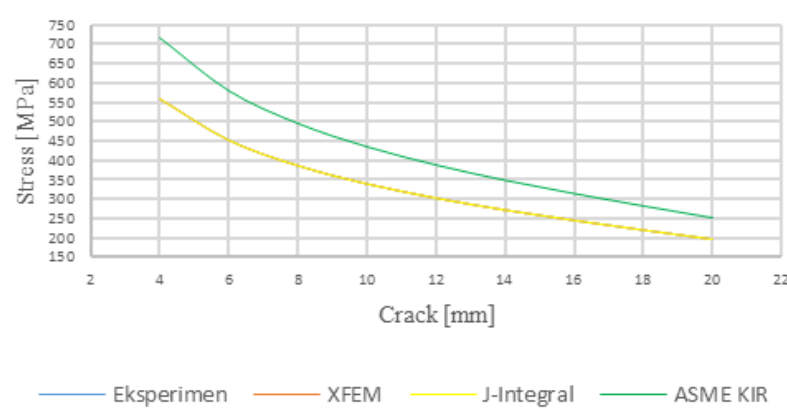

Gambar 7. Kurva Tegangan Kritis Baja A36

Pada Gambar 7 menunjukkan bahwa tegangan kritis dari ketiga metode (eksperimen, XFEM dan J-Integral) memiliki perbedaan nilai yang kecil. Kurva dari ketiga metode menunjukkan safety factor yang lebih tinggi daripada kurva tegangan kritis ASME $\mathrm{K}_{\mathrm{IR}}$.

\section{KESIMPULAN}

Stress Intensity Factor (SIF) baja A36 spesimen 1 sampai dengan spesimen 9 memiliki nilai yang berbeda pada masingmasing metode. Hal ini dikarenakan nilai $\mathrm{K}_{\mathrm{I}}$ dan J-Integral tidak konstan disepanjang crackfront.

Berdasarkan Stress Intensity Factor (SIF) baja A36 memberikan hasil berupa fracture toughness baja A36 sebagai berikut:

- Hasil eksperimen menghasilkan fracture toughness sebesar $1413.7154 \mathrm{MPa} \sqrt{\mathrm{mm}}$.

- Pendekatan XFEM pada setiap K mode I menghasilkan fracture toughness sebesar $1412.6214 \mathrm{MPa} \sqrt{\mathrm{mm}}$.

- Pendekatan J-Integral menghasilkan fracture toughness sebesar 1414.7809 $\mathrm{MPa} \sqrt{\mathrm{mm}}$.

Relatif terhadap hasil perhitungan fracture toughness secara eksperimen, diperoleh error sebesar $0.077 \%$ untuk pendekatan XFEM dan 0.075\% untuk pendekatan J-Intergral.

Berdasarkan fracture toughness baja A36 dari ketiga metode didapatkan tegangan kritis yang nilainya tidak jauh berbeda pada setiap metode yang dihasilkan.

\section{DAFTAR PUSTAKA}

[1] H. Amanto and D. Daryanto, Ilmu bahan, vol. 1999. Jakarta: Bumi Aksara, 1999.

[2] D. R. Askeland, The Science and Engineering of Materials. Boston, Massachusetts: PWS Engineering, 1985.

[3] DNV GL, “CLASS GUIDELINE Finite element analysis.” DNV GL, 2015.

[4] D. Broek, Elementary Engineering Fracture Mechanics, 3rd rev. ed. Boston: Kluwer Boston, 1982.

[5] R. W. Hertzberg, R. P. Vinci, and J. L. Hertzberg, Deformation and Fracture Mechanics of Engineering Materials, 5th ed. Hoboken: John Wiley \& Sons, Inc, 2012.

[6] J. R. Rice, "Mathematical Analysis in the Mechanics of Fracture," in Fracture: An Advanced Treatise, vol. 2, H. Liebowitz, Ed. New York: Academic Press, 1968, pp. 191-311. 